\title{
Attack induced by second-order schedules of reinforcement
}

\author{
RANDALL K. FLORY and SHARON J. ROBINSON \\ Hollins College, Roanoke, Virginia 24020
}

\begin{abstract}
Food-deprived pigeons were exposed to tandem, chain, and brief-stimulus second-order schedules in which the completion of three 80 -sec fixed-interval components was followed by food delivery. Two birds attacked a nearby stuffed pigeon shortly after the presentation of either food-paired or food-nonpaired visual stimuli, as well as following food. The third subject exhibited predominantly postfood attack. These results suggest that the locus of scheduleinduced attack can be controlled by a stimulus event, whether food delivery or key-color change, that reliably precedes a relatively long period of food unavailability.
\end{abstract}

Aggressive behavior against live or inanimate targets has been induced by the transition from a period of frequent food delivery to one during which food is never delivered (Azrin, Hutchinson, \& Hake, 1966; Thompson \& Bloom, 1966) and by various response-dependent as well as response-independent food schedules (see reviews by Fredericksen \& Peterson, 1977; Looney \& Cohen, 1982). Schedule-induced attack typically occurs shortly after food delivery and decreases in probability with the passage of time from the onset of the postreinforcement period.

It is possible that induced attack predominantly occurs as a postreinforcement phenomenon because reinforcer delivery according to many intermittent schedules, especially fixed or periodic ones, has discriminative properties that signal a period during which the probability of further reinforcement is either zero or relatively low. It is also possible that attack is induced by the stimulus factors associated with reinforcer receipt (e.g., consummatory or prandial stimuli subsequent to food ingestion) or to the supposed aversive stimulus factors associated with the termination of reinforcerrelated activity (Azrin et al., 1966; Gentry, 1968; Hutchinson, Azrin, \& Hunt, 1968). Finally, it is possible that both factors contribute to the induction of attack behavior.

Since simple reinforcement schedules confound the discriminative and postingestional properties of intermittent food delivery, researchers have used secondorder schedules to isolate the separate contributions of these two factors for the occurrence of scheduleinduced drinking (Allen \& Porter, 1977; Allen, Porter, \& Arazie, 1975; Corfield-Sumner, Blackman, \& Stainer, 1977; Porter, Arazie, Holbrook, Cheek, \& Allen, 1975;

This research was supported in part by a Faculty Research Grant from Hollins College to the first author. We wish to thank Betty Loving for her assistance in preparation of the manuscript. Reprints may be obtained from Randall Flory, Department of Psychology, Hollins College, Roanoke, Virginia 24020.
Rosenblith, 1970; Flory \& Blosser, Note 1) and scheduleinduced escape (Brown, 1975). In one segment of his doctoral dissertation, Brown (1975) also reported the occurrence of schedule-induced attack following a foodpaired brief stimulus, as well as following food, in two of four pigeons.

In a second-order schedule, a pattern of behavior engendered by one schedule is treated as a unitary response that itself is reinforced according to some schedule of primary reinforcement (Kelleher, 1966). For example, a second-order schedule that arranges that completion of an 80-sec fixed-interval (FI) schedule is reinforced according to a fixed-ratio (FR) 3 schedule of food delivery is designated as FR 3 (FI 80 sec). Secondorder schedules may be arranged such that a brief stimulus occurs either (1) upon completion of those schedule components that do not terminate with food, thus resulting in a stimulus-nonpaired ( $\mathrm{Snp}$ ) condition, or (2) upon completion of all schedule components including those terminating with food, thus resulting in a stimulus-paired $\left(\mathrm{S}^{\mathrm{P}}\right)$ condition.

To assess the factor(s) responsible for the postfood occurrence of induced attack and to determine whether this behavior can occur following stimulus events other than food ingestion, the present study exposed pigeons to several second-order schedules of reinforcement of food-paired as well as food-nonpaired brief stimuli.

\section{METHOD}

\section{Subjects}

Three male White Carneaux pigeons, approximately 3-5 years of age, were used. Each was maintained at $75 \%$ of its free-feeding body weight, and each had previously exhibited scheduleinduced attack.

\footnotetext{
Apparatus

One end of a pigeon chamber contained a food magazine located behind a $4.5 \times 6.0 \mathrm{~cm}$ aperture and a response key located $9.0 \mathrm{~cm}$ above the aperture. At the other end of the chamber, approximately $50.0 \mathrm{~cm}$ from the stimulus panel, was a taxidermically prepared White Carneaux pigeon, the head and throat areas of which were covered with closely cropped white
} 
fur, so that the model would be more durable. A force of $60 \mathrm{~g}$ or more applied to the model's head defined an attack. Onlythose switch closures separated by at least $150 \mathrm{msec}$ were recorded as discrete attacks. The target was illuminated throughout experimental sessions.

\section{Procedure}

Each pigeon was trained to keypeck on an FI 80 -sec food schedule with the target inaccessible and the response key blue. During each 8-sec grain presentation, the hopper was illuminated with red light, and all chamber lights except those above the target were extinguished. Following 15 sessions, the target was introduced. When the rate and index of curvature (Fry, Kelleher, \& Cook, 1960) for keypecking, as well as the rate and conditional probability of attack, showed little systematic variability over five sessions, each pigeon was exposed to a series of second-order schedules in which the completion of every third FT 80-sec schedule was followed by food delivery. Following stability of attack induced by a tandem FR 3 (FI 80-sec) schedule during which the key remained blue between food deliveries, birds were exposed to a second-order FR 3 (FI 80$\left.\sec : S^{n p}\right)$ schedule, during which a brief visual stimulus (a .70-sec change in key color from blue to white plus a simultaneous flash of auxiliary houselights) was presented following completion of each first and second but not third FI 80-sec component. Next, pigeons were exposed to an FR 3 (FI 80-sec:Sp) schedule, during which the same brief stimulus was presented upon completion of every FI component. During the subsequent chain FR 3 (FI 80-sec) schedule, the key was green during the first, yellow during the second, and blue during the third FI component. Pigeon 4 was then exposed to two additional FR 3 (FI 80-sec:Sp) conditions. Brief stimulus presentations were accompanied by illumination of the red feeder light in the first of these two conditions ( $\mathrm{S}^{\mathrm{p}}$ ) and by illumination of the feeder light and brief activation of the grain hopper in the second $\left(\mathrm{S}^{\mathrm{p} 3}\right)$. All three birds were then reexposed to the simple FI 80sec schedule and then to an extinction condition, during which the first keypeck after $80 \mathrm{sec}$ was followed by the food-paired brief stimulus but no food. A third exposure to the 80 -sec FI terminated the study.

Daily sessions consisted of 20 food deliveries. A protective contingency, which arranged that a schedule component could not end until at least $10 \mathrm{sec}$ had elapsed since the last attack, was employed to reduce the possibility that attack behavior would be reinforced adventitiously.

\section{RESULTS}

Figure 1 shows the mean percentage of FI component schedules containing at least one attack based on the last five sessions of each experimental condition. Although it does not indicate the intensity of attack occurring per attack interval, this conditional probability measure of attack is unaffected by differences in the duration of FI components, and it clearly differentiates the stereotyped pattern of attack behavior exhibited by Pigeon 4 from that exhibited by the other two birds. Whereas Pigeon 4 seldom attacked except following food delivery, Pigeons 5 and 6 showed substantial attack not only following food, but also within other components of second-order schedules. Both birds showed considerable attack following the presentation of food-paired brief stimuli. Pigeon 6, in fact, attacked more following the second paired stimulus than following food. Pigeon 5 also exhibited attack,

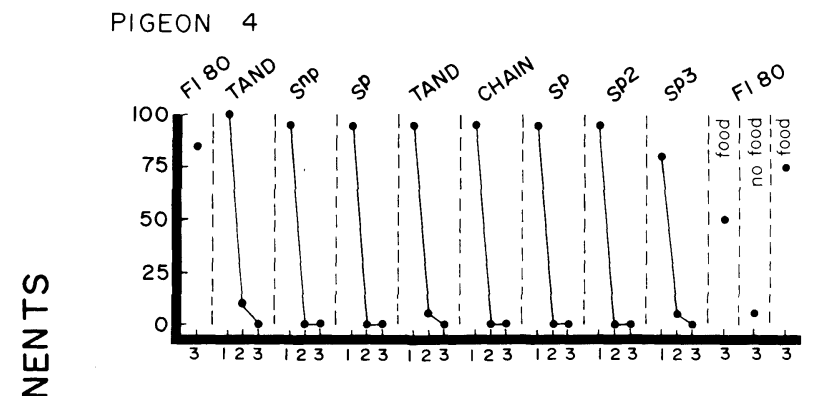

PIGEON 5

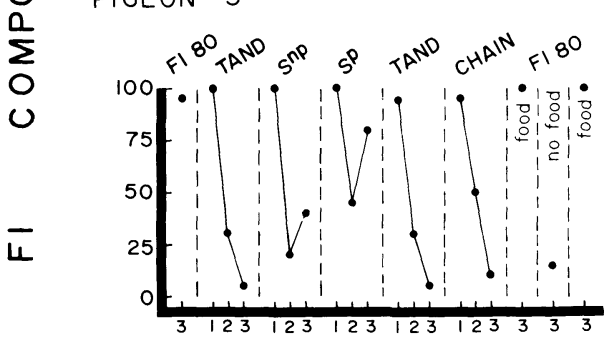

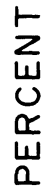

PIGEON 6

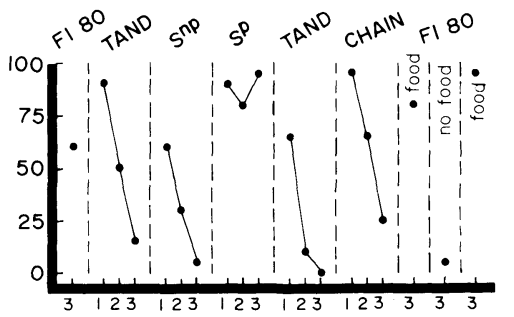

FI COMPONENTS

Figure 1. Percentage of session fixed-interval schedule components in which at least one attack occurred. Each point represents the mean of the final five sessions at each condition.

although to a lesser extent, following the presentation of brief stimuli that were unpaired with food. In addition, during exposure to the chain schedule, Pigeons 5 and 6 attacked in a higher percentage of second and third FI components than during comparable tandem conditions. For all three birds, the complete elimination of food resulted in near-zero levels of attack. When rate of attack was plotted across experimental conditions, results very similar to those shown in Figure 1 resulted.

An analysis of index-of-curvature measures revealed that the keypeck behavior of Pigeon 4 showed little or no within-component positive acceleration in rate during any second-order schedule except the $\mathrm{S}^{\mathrm{p}^{2}}$ and the $\mathrm{S}^{\mathrm{p}^{3}}$ conditions when some evidence of typical FI patterning was observed. For Pigeons 5 and 6, however, typical "scalloped" patterning of keypeck behavior occurred within components of the paired and nonpaired briefstimulus second-order schedules, and to a lesser extent during the second and third components of the chain schedule. 
Figure 2 shows sample cumulative records of keypecking and attack behavior for Pigeon 5. Each keypeck stepped the response pen in an upward direction, and food delivery reset this pen to baseline. Attacks are indicated by brief downward deflections of the response pen, and the completion of each FI 80-sec component schedule is indicated by a deflection of the event pen. During the FI food schedule (Record a) and the initial tandem schedule (Record b), attack predominantly occurred shortly after food delivery. Records $c$ and d, however, show the relatively consistent occurrence of attack behavior shortly after the presentation of paired as well as nonpaired brief stimuli, and they also illustrate the typical "scalloped" pattern of keypecking that occurred during these two second-order conditions for Birds 5 and 6. Record $f$ shows that Pigeon 5 occasionally attacked within the second and third FI components of the chain and that some minimal degree of FI patterning occurred during these later chain components.

For all birds, the topography of attack following brief-stimulus presentations and following the onset of chain schedule components closely resembled that observed following food delivery. Attacks were primarily

(a)
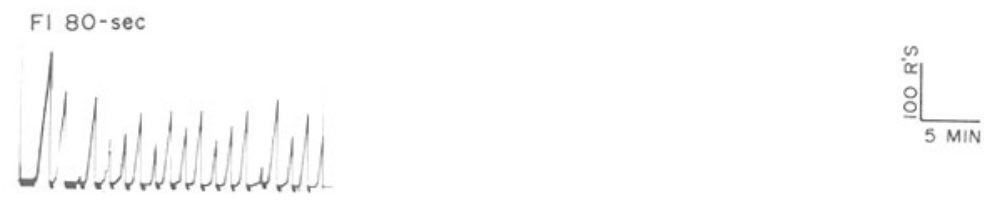

TAND FR 3 (FI 80-sec)

(b)

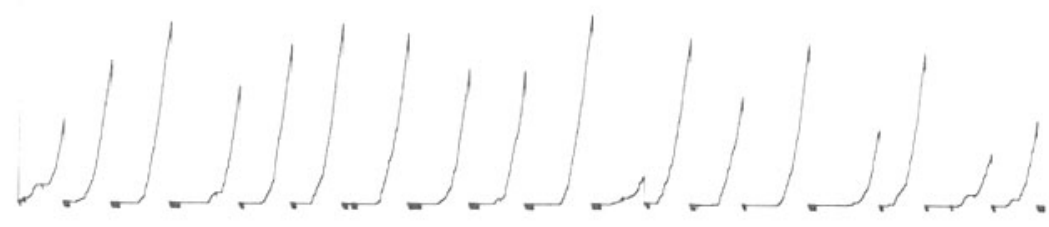

FR 3 (FI 80-sec: $S^{n p)}$

(c)

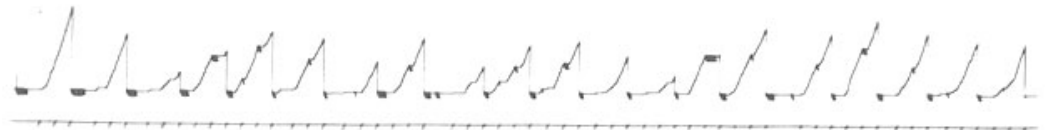

FR 3 (FI 80-sec: $S^{P}$ )

(d)

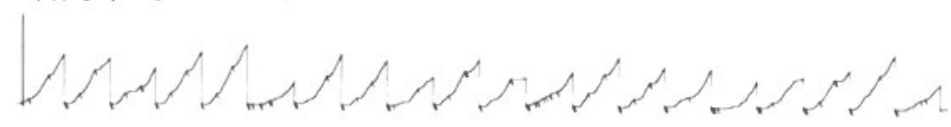

(e)

TAND FR 3 (FI 80-sec)

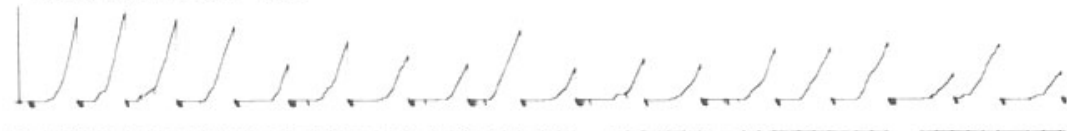

CHAIN FR 3 (FI 80-sec)

(f)

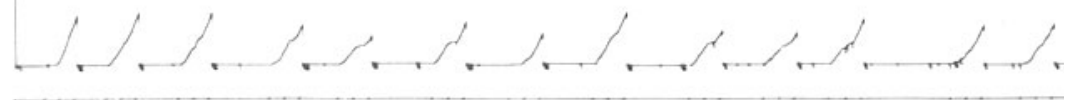

Figure 2. Sample cumulative records of Pigeon 5. Each keypeck stepped the response pen in an upward direction, and food delivery reset this pen. Attacks are indicated by downward deflections of the response pen, and completion of each FI component is indicated by deflection of the event pen. 
directed at the eyes, head, and throat areas of the target and were often preceded by crouching and wing flapping.

\section{DISCUSSION}

The observation that two of three birds in the present study exhibited schedule-induced attack shortly after the periodic presentation of nonfood stimuli that signaled a period of food absence indicates that such behavior is not necessarily a postfood phenomenon. The results of Pigeons 5 and 6 corroborate those of Brown (1975), who found that two of four pigeons exposed to a second-order FR 3 (FI 120-sec) schedule attacked immediately following food-paired brief-stimulus presentations, as well as following food. In agreement with the present findings. Porter and Kenshalo (1974) and Rosenblith (1970) found that monkeys and rats exposed to second-order schedules exhibited schedule-induced drinking following the presentation of a brief stimulus that was paired with food, but to a lesser extent than following food. Similarly, Brown (1975) found that the escape behavior of pigeons exposed to fixed second-order schedules was confined to periods immediately following food or food-paired stimuli.

It is likely that the failure of Pigeon 4 to attack following presentation of nonfood brief stimuli across all but the final second-order schedule condition was related to the failure of stimulus presentations to develop discriminative control over keypecking behavior in this bird. Only when the paired brief stimulus was quite salient (i.e., the normal brief stimulus plus the red feeder light plus operation of the food hopper) did Pigeon 4 show some degree of poststimulus attack as well as poststimulus FI patterning of keypeck behavior.

As in previous studies investigating the occurrence of scheduleinduced behavior during second-order schedules, all three birds exhibited more attack behavior following food delivery than following nonfood stimulus presentations. This observation suggests that although the discriminative factors of a stimulus that signals a period of low reinforcement probability may be sufficient to control the location of induced attack, other stimulus factors uniquely associated with food may further enhance the amount of such behavior. In the present study, one of these unique factors was that each food delivery signaled a longer period of food absence than did nonfood stimulus presentations. It is also possible that more attack occurred following food than following stimulus presentation because the abrupt termination of eating might reasonably be expected to be more aversive for a food-deprived animal than would the removal of a nonfood stimulus.

\section{REFERENCE NOTE}

1. Flory, R. K., \& Blosser, S. L. Drinking induced by secondorder schedules of reinforcement: $A$ reevaluation. Paper presented at the meeting of the Eastern Psychological Association, Baltimore, Md., 1982.

\section{REFERENCES}

Allen, J. D., \& Porter, J. H. Sources of control over scheduleinduced drinking produced by second-order schedules of reinforcement. Physiology \& Behavior, 1977, 18, 853-863.

Allen, J. D., Porter, J. H., \& Arazie, R. Schedule-induced drinking as a function of percentage reinforcement. Journal of the Experimental Analysis of Behavior, 1975, 23, 223-232.

Azrin, N. H., Hutchinson, R. R., \& Hake, D. F. Extinctioninduced aggression. Journal of the Experimental Analysis of Behavior, 1966, 9, 191-204.

Brown, T. G. Aversive properties of briefly presented stimuli: Escape behavior induced by second-order schedules of reinforcement. Unpublished doctoral dissertation, University of Maine at Orono, 1975.

Corfield-Sumner, P. K., Blackman, D. E., \& Stainer, G. Polydipsia induced in rats by second-order schedules of reinforcement. Journal of the Experimental Analysis of Behavior, $1977,27,265-273$.

Frederiksen, L. W., \& Peterson, G. L. Schedule-induced aggression in humans and animals: A comparative parametric review. Aggressive Behavior, 1977, 3, 57-75.

Fry, W., Kelleher, R. T., \& Cook, L. A mathematical index of performance on fixed-interval schedules of reinforcement. Journal of the Experimental Analysis of Behavior, 1960, 3, 193-199.

GentRY, W. D. Fixed-ratio schedule-induced aggression. Journal of the Experimental Analysis of Behavior, 1968, 11, 813-817.

Hutchinson, R. R., Azrin, N. H., \& Hunt, G. M. Attack produced by intermittent reinforcement of a concurrent operant response. Journal of the Experimental Analysis of Behavior, $1968,11,489-495$.

Kelleher, R. T. Conditioned reinforcement in second-order schedules. Journal of the Experimental Analysis of Behavior, 1966, 9, 475-485.

Looney, T. A., \& Cohen, P. S. Aggression induced by intermittent positive reinforcement. Biobehavioral Reviews, 1982, 6, 15-37.

Porter, J. H., Arazie, R., Holbrook, J. W., Cheek, M. S., \& Allen, J. D. The effects of variable and fixed secondorder schedules on schedule-induced drinking in the rat. Physiology \& Behavior, 1975, 14, 143-149.

Porter, J. H., \& Kenshalo, D. R., Jr. Schedule-induced drinking following omission of reinforcement in the rhesus monkey. Physiology \& Behavior, 1974, 12, 1075-1077.

Rosenblith, J. Z. Polydipsia induced in the rat by a secondorder schedule. Journal of the Experimental Analysis of Behavior, 1970, 14, 139-144.

Thompson, T., \& Bloom, W. Aggressive behavior and extinctioninduced response rate increase. Psychonomic Science, 1966, 5, 335-336.

(Received for publication September 24, 1982.) 